\title{
EFFECTS OF WINERY VISITOR GROUP SIZE ON GRATITUDE AND OBLIGATION
}

Published in the Journal of Travel Research, 2008, 47(1), 104 - 112

\author{
NATALIA KOLYESNIKOVA* \\ Department of Nutrition, Hospitality and Retailing \\ Box 41162 \\ Texas Tech University \\ Lubbock, Texas 79409-1162, USA \\ Tel: (806) 742-3068 (extension 227) \\ Fax: (806) 742-3042 \\ E-mail: n.kolyesnikova@ttu.edu
}

\author{
TIM H. DODD \\ Department of Nutrition, Hospitality and Retailing \\ Box 41162 \\ Texas Tech University \\ Lubbock, Texas 79409-1162, USA \\ Tel: (806) 742-3031 (extension 239) \\ Fax: (806) 742-3042 \\ E-mail: tim.dodd@ttu.edu
}

*Corresponding Author 
Natalia Kolyesnikova is an Assistant Professor at Texas Tech University where she teaches courses at the Department of Nutrition, Hospitality, and Retailing. She is also employed by the Texas Wine Marketing Research Institute. Dr. Kolyesnikova's research interests focus mostly on wine consumer behavior, wine marketing, and wine tourism.

Tim H. Dodd is the James and Kailee Young Regents Professor of Restaurant Hotel Management Department and Director of the Texas Wine Marketing Research Institute at Texas Tech University. He also serves as the Associate Dean of Operations in the College of Human Sciences. Dr. Dodd has worked with the New Zealand grape and wine industry and served as President for the Texas Wine and Grape Growers Association. His research focuses on wine tourism and consumer behavior. 


\title{
EFFECTS OF WINERY VISITOR GROUP SIZE \\ ON GRATITUDE AND OBLIGATION
}

\begin{abstract}
Building on reciprocity theory, the current study explores whether wine tourists feel a need to buy wine at tasting rooms due to a perceived need to reciprocate for services received. In this research, wine and souvenirs bought fully or partly out of the desire to repay hospitality and services received are defined as gratuity purchasing. Specifically, the study investigates the role of gratitude and obligation in wine tourist purchasing behavior. The results indicate that the higher visitor feelings of gratitude and obligation while at a winery, the bigger the expenditures. In addition, the research examines the effect of visitor group size on purchasing. It appears that visitors who travel to wineries in smaller groups experience higher levels of gratitude and obligation than visitors of larger groups. Consequently, visitors who come to wineries in smaller groups tend to spend more money on wine and/or souvenirs than larger groups. Managerial implications are discussed.
\end{abstract}

Keywords: wine tourism, travel party size, gratitude, obligation 
Wine tourism is big business across the United States and worldwide. According to the latest report on the economic impact of California wine, 19.7 million people visited Californian wine-producing areas in 2006 (Motto Kryla \& Fisher 2006). Tourism directly related to the wine industry in California resulted in expenditures of \$2 billion (Motto Kryla \& Fisher 2006). California has a long history associated with wine. However, wine tourism also has been developing in other U.S. states, which have not been traditional wine making regions. For example, the Texas Wine Marketing Research Institute reported that the overall impact of the wine industry on the state economy was due to substantial expenditures in hospitality and tourism related to the wine industry. In 2005, wine tourism expenditures in Texas were an estimated \$96.5 million (Dodd, Kolyesnikova, and Choi 2005).

In the worldwide context, Australia was one of the first countries to recognize that both national tourism and the wine industry can capitalize on the growing interest in visiting wine regions. The Winemakers Federation of Australia (2005) reported that the estimated value of wine tourism in Australia is nearly $\$ 1$ billion. Wine tourism is also the fastest growing industry in South Africa (South African Wine Industry Information \& Systems 2004). Recently, some Eastern European countries like Hungary, have begun to establish wine trails in an effort to attract Western European tourists (Hall, Sharples, Cambourne, and Macionis 2000). Thus, wine tourism can provide positive contributions to both the wine and tourism industries, as well as to regional economies.

The current study aims to demonstrate the importance of consumer behavior in wine tourism. Specifically, the study focuses on purchasing behavior of winery visitors. Tasting room sales can be extremely important for business profitability, especially for small wineries that often do not have sufficient production to sell their wine through wholesalers. According to 
a recent tasting room survey, smaller wineries producing up to 5,000 cases annually report that nearly 70 percent of their sales come from their tasting rooms (Barclay 2006). An understanding of tasting room visitor behavior is crucial for wineries managers. Such understanding can help provide important insights into who the wine tourists are, but more importantly, how the decision to buy (or not to buy) wine at the end of the visit is being formed.

\section{RATIONALE FOR THE STUDY}

Although there has been a substantial growth of studies on wine tourists in recent years, the amount of research is extremely small compared to other service industries such as retailing or hospitality. The summary of research on wine tourists provided by Mitchell, Hall, and McIntosh (2000) suggested that much of the early research on winery visitors has been conducted from the wineries' perspective (supply-side research) rather than the visitors' perspective (demand-side).

In the last decade, however, researchers began to focus directly on wine tourists as the need for understanding tourists' behavior had been increasingly recognized in the industry. Studies on wine tourists focused mainly on consumers' socio-demographic characteristics (Dodd and Bigotte 1997), psychographic attributes (Charters and Ali-Knight 2002), combined with attitudinal measures (Dodd and Gustafson 1997). Several consumer attributes were examined, including product and purchase involvement (Yuan and Dodd 2001), experience and social interaction (Groves, Charters, and Reynolds 2000), occasion (Hall and Lockshin 1999), and consumer knowledge about wine (Dodd, Laverie, Wilcox, and Duhan 2005). These factors have been found explanatory for wine purchasing behavior. In order to compile a comprehensive profile of wine tourists, researchers need to address wine tourist behavior from multiple 
perspectives. However, there seems to be a gap in the existing literature with regards to sociological perspective of wine tourists' behavior.

Consumer purchasing decision is a complex and multifaceted phenomenon, and the real reasons for purchasing are not always straightforward. In the tasting room visit circumstance, wine purchasing sometimes can be explained simply by objective characteristics of the product, for example price of the wine. Subjective consumer preferences, such as taste of wine or preferences for certain varietals, are likely to have considerable impacts on purchasing decisions as well. In many instances, however, the true reasons for purchasing may be subliminal and difficult to identify. For example, visitors may feel grateful to winery personnel for the quality of services received. Visitors may then decide to purchase wine to show gratitude for high quality services, sometimes even if they did not necessarily like the taste of wine.

Alternatively, a sense of obligation, rather than gratitude, may be dominant. This sense of obligation may result from the free tasting offered at the winery. Some consumers may also feel that leaving the winery empty-handed may be viewed as improper behavior, especially since visits to tasting rooms occur in public conditions. Again, visitors may or may not necessarily like the wine, but decide to buy it anyway for reasons other than taste - for example, due to the sense of obligation.

The current study attempts to investigate these potential feelings of gratitude and obligation that may prompt purchasing at wineries. Gratitude and obligation may lead to what we suggest to be called gratuity purchasing. According to the Oxford English Dictionary, “gratuity” means, "a gift or present (usually of money), given voluntarily, without claim or demand, often in return of favor or services, the amount depending on the inclination of the giver" (Simpson and Weiner 1989, p. 780). The term seems pertinent to the context of 
investigation. Therefore, we suggest that gratuity purchases are products or services bought by consumers fully or partly due to a perceived need to repay benefits received from a business or its employees.

This approach calls for addressing the issue of purchasing behavior from the sociological perspective. No previous studies were located that addressed wine tourist behavior from this standpoint. Several wine marketing researchers previously recognized the importance of the social context for wine consumption (Bruwer, Li, and Reid 2002, Groves et al. 2000, Spawton 1991). In social situations, people may be concerned about what others will think of their wine selection and how they will appear if they make a poor choice (Hall and Winchester 2000). Yet, previous studies did not use social environment as the subject of investigation. The role of gratitude and obligation has not been examined in the wine tourism research. The current study will examine feelings of gratitude and obligation that potentially may lead to gratuity purchasing.

Furthermore, the study investigates whether expenditures at wineries are influenced by the presence of travel companions. It has been estimated that as much as $80 \%$ of all buying decisions are influenced by someone's direct recommendation (Voss 1984). Tourists' choices of destination, as well as purchasing decisions, may be influenced by travel companions.

To summarize, the purpose of the study is to explore whether or not winery visitors feel a need to buy wine due to a perceived need to repay services received at tasting rooms. The study also examines whether differences exist between smaller and larger groups of visitors in terms of gratitude, obligation, and purchasing behavior at wineries. By drawing on consumer behavior, marketing, and social psychology literature, the study will extend current research on wine tourists.

\section{THEORETICAL BACKGROUND}


Gratuity purchasing can be theoretically supported by a concept known in social psychology as reciprocity. The basic proposition of the reciprocity rule is that people feel obligated to make future repayments for what they have received. Simply put, people feel a need to repay, in kind, what other people have provided them. For example, if somebody helps us, we often feel a need to repay the kindness later. Most people almost instantly feel a sense of obligation after someone treats them kindly (Whatley, Webster, Smith, and Rhodes 1999). According to the reciprocity norm, people feel an emotional need to reciprocate for positive behavior received.

In explaining how the reciprocity rule works, the author of the original reciprocity theory Alvin Gouldner (1960) stated, "Insofar as men live under such rule of reciprocity, when one party benefits from another, an obligation is generated. The recipient is now indebted to the donor, and he remains so until he repays" (p. 174). The norm of reciprocity then creates motives for returning benefits.

Social scientists argue that reciprocity is one of the earliest and most powerful moral principles taught to children, and therefore, is a social norm (Berkowitz 1972, Cialdini and Rhoads 2001, Elster 1989, Whatley et al. 1999). Stated differently, we are taught from early childhood that returning kindness is simply the proper thing to do. Further review of the theoretical background leads to the introduction of the two key forces that explain the norm of reciprocity, namely gratitude and obligation.

\section{GRATITUDE AND OBLIGATION}

In his original theory, Gouldner (1960) suggested that the two conditions that make the reciprocity rule work, are gratitude and obligation. Gouldner noted that the two states operate as 
independent predictors of reciprocal behavior, "the sentiment of gratitude joins forces with the sentiment of rectitude and adds a safety-margin in the motivation to conformity" (p. 176).

Attempts have been made to investigate the impact of these two factors on reciprocal behavior. There is empirical evidence that gratitude can be a predictor of reciprocal actions (Goei and Boster 2005, Graham 1988). Several studies implied that gratitude for a received favor can potentially explain compliance with further requests from the favor-giver (e.g., Emmons and Crumpler 2000, McCullough, Kilpatrick, Emmons, and Larson 2001). The studies on obligation, however, provided inconsistent results regarding the role of obligation in the favor-compliance relationships. Some studies have found that favors increase obligation, and obligation, in turn, increases compliance (Greenberg and Frisch 1972, Greenberg and Saxe 1975). Others reported no relationship between obligation and compliance (Goei and Boster 2005).

This research aims to empirically test reciprocity theory in the consumer behavior context. It is expected that if visitors' experiences at wineries are enjoyable, they may feel appreciative of the staff who provided services. Therefore, visitors are likely to develop a sense of gratitude. These feelings, in turn, may lead to a perceived need to buy wine and/or wine souvenirs at the end of their visits. At least subconsciously, visitors understand that the winery personnel will benefit from the purchase. In view of the reciprocity norm, the exchange of benefits should be mutually beneficial. So, on the one hand, consumers may see purchasing as a way to express their gratitude. Alternatively, purchasing can occur because of the sense of obligation, for example a perceived need to comply with the reciprocity norm. In summary, there are good theoretical reasons to believe that gratitude and obligation may impact winery visitor purchasing behavior. 
$\mathbf{H}_{1}$ : The stronger the feelings of gratitude and obligation that wine tourists experience during their visit to a winery, the bigger the expenditures per person.

Another particular point of interest is to explore whether gratitude and obligation can be distinguished operationally. While most researchers agree that the terms are conceptually different, it is not until recently that attempts have been made to operationalize the two variables separately (Goei and Boster 2005). Their results demonstrated that gratitude and obligation can be approached quantitatively and should be empirically and operationally distinguished.

We intend to further explore the operational distinction between gratitude and obligation. Due to the exploratory nature of this study, a research question was developed.

$\mathbf{R Q}_{1}$ : Are gratitude and obligation conceptually and operationally different constructs? In order to produce a more in-depth investigation of the effect of reciprocity in consumer behavior, the current study aims to examine additional factors that may play an important role in the hypothesized effects of gratitude and obligation. With a very few exceptions, the existing research on reciprocity did not take into consideration additional external or internal factors that may influence individual levels of gratitude and obligation. Some researchers examined the effect of external conditions (public versus private) on the reciprocity norm (Whatley et al. 1999), and found that reciprocity works better in public conditions. Relationships between a beneficiary and a benefactor were also investigated. The results suggested that people more often comply with requests of those who have done them small favors (Boster, Rodriguez, Cruz, and Marshall 1995, Howard 1995), especially if the relationship between a beneficiary and a benefactor are close (Bar-Tal, Bar-Zohar, Greenberg, and Hermon 1977), or expected to be longtermed (Pervan, Bove, and Johnson 2004). 
There appears a need to look at additional factors that can potentially influence the rule of reciprocity. In the current research, gratuity purchasing is approached with respect to the number of visitors in the group.

\section{GROUP TRAVEL}

The idea that other people's opinions impact customer choice of products and activities has been suggested for some time (Holbrook, O‘Shaughnessy, and Bell 1990, McCall and Simmons 1978, Ward 1974). Despite consumer researchers' long recognition that social context (i.e., presence of other people) is of great significance to product consumption and activities choices, there is a lack of research related to the social nature of consumer behavior in tourism.

Group travel has been approached in the tourism literature mostly through the examination of reference groups influences. Several researchers investigated reference groups influences on information sources (e.g., Gitelson and Crompton 1983, Hsu, Kang, and Lam 2006, Snepenger, Meged, Snelling, and Worrall 1990). Spousal influences on vacation planning/buying have been examined (e.g., Jenkins 1978, Kang and Hsu 2004, Litvin, Xu, and Kang 2004), as well as the effect of different reference groups (i.e., family, friends/relatives, travel agents) on tourist behavior (Hsu et al. 2006).

Reference group influences were of less significance to the current study. The research focuses on the number of people in the group with respect to wine tourist purchasing. In terms of travel spending, previous research usually showed that larger group travel is associated with lower expenditures than average, and researchers usually explain this trend by the economies of scale related to group travel (Laesser and Crouch 2006). Following this explanation, visitors of smaller and larger groups are expected to differ in terms of their purchasing at wineries. In particular, we expect that: 
$\mathbf{H}_{2}$ : The smaller the group of wine tourists, the bigger the expenditures at wineries.

Although the economies of scale explanation presents reasonable rationale for group travel expenditures, we suggest that reciprocity theory can offer further clarification to differences in travel expenditures between smaller and larger groups of tourists. The current research approaches spending at wineries not merely as travel expenditures, but rather as gratuity purchasing - that is, purchasing due to potential feelings of gratitude and/or obligation. Of particular interest to this research is the relationship between gratitude, obligation, and the number of travel companions in the group.

Previous research has indicated that reciprocity works better in public conditions than in private conditions (Cialdini 2001, Whatley et al. 1999). Simply put, people are more likely to reciprocate if they know that their actions are visible to other people. In the context of the current study, smaller groups actions are more visible. It is also reasonable to suggest that visitors of smaller groups have more opportunities to interact with the winery personnel and therefore, may experience higher levels of gratitude, and possibly, obligation to reciprocate (i.e., purchase wine) at the end of their visit to a winery.

$\mathbf{H}_{3}$ : Wine tourists who visit wineries in smaller groups experience higher levels of gratitude and obligation than visitors of larger groups.

\section{METHOD}

\section{Sample}

The population of interest was wine tourists. Six wineries geographically dispersed throughout the state of Texas were used as sites to gather data from winery visitors. Texas was chosen as a study site because of a dynamic development of its wine industry. Although Texas has not been a traditional wine making region, the Texas wine industry has come a long way 
since its emergence in the late 1970s. Within a relatively short time period, the number of Texas wineries increased dramatically, from 27 in 1990 to more than 100 wineries in 2006 (Dodd et al. 2005). Texas has a variety of winery types, with some large upscale facilities with substantial staff involvement to small sheds where the owner is the wine maker, tour guide, and involved in all aspects of the business. For the current study, a conscientious effort has been made to control for these factors. Different types of wineries were used based on the winery size, product specialization, and reputation. There was also a range of wine prices at the chosen wineries, which added to the diversity of the data collection sites.

The sample was drawn from people 21 years of age and older who visited the sampled wineries. The study employed a survey method. Questionnaires were collected over a threemonth period during the summer 2005, with the majority being collected during weekends. Weekends were selected as the best time for collecting data because Saturday and Sunday are the busiest days for most wineries. A quota of 50 questionnaires from each winery was set in order to obtain a reasonable sample from each of the six wineries and an adequate total number of responses.

\section{Procedures}

Research personnel collected data by personal distribution of the questionnaire to visitors at the sampled wineries. As visitors were leaving the winery, the researcher approached them, introduced the purpose of the study, and asked if they were willing to participate in the survey. If visitors agreed to participate, they were provided with the questionnaire and were asked to return it completed before leaving the winery.

It is important to note that attempts were made to include both visitors who bought wine and/or souvenirs at the tasting rooms and those who did not make a purchase. In other words, 
the researcher approached all visitors, regardless of whether or not they made a purchase at the winery. Those participants who purchased wine and/or souvenirs used actual receipts to fill out the amount of purchase. The decision to include all visitors was determined by the purpose of the study to examine feelings of gratitude and obligation, or lack thereof, while at a winery. A total of 357 questionnaires were collected and analyzed.

\section{Instrument Development}

The questionnaire was designed to measure a number of factors that may affect consumer purchasing decisions at wineries. To our knowledge, previous research in social psychology on gratitude and obligation focused on effect of a favor on compliance. Feelings of gratitude and obligation were evoked though manipulation of a favor (e.g., a stranger (confederate) unexpectedly brings a soft drink (Regan 1971) or a project partner (confederate) brings an extra copy of needed materials (Goei and Boster 2005). The current study was not subject to experimental control. It did not seem realistic to experimentally induce feelings of gratitude and/or obligation in a winery setting and previous pen-and-paper measurements of gratitude and obligation (Goei and Boster 2005) could not be directly applied to the current study. Thus, using various techniques, a new multi-item scale was developed to measure the degree of gratitude and obligation experienced by wine tourists while visiting a tasting room. Several items were included on the scale to allow for elimination of poor performing items through pre-testing.

Following Churchill's (1979) recommendations for scale development, both pre-testing and a pilot study were employed. The first pretest was administered to 59 undergraduate students majoring in Hospitality Management at a large public university in the southwestern United States. The purpose of the pre-testing was to generate a comprehensive list of items. Two sets of simulated scenarios were developed to create situations similar to visiting a winery. 
One scenario featured a visit to a brewery with beer tasting and a tour; the other described a visit to a department store where a make-up consultant offered a free make-over. The participants were asked to describe feelings that they would experience at the end of these events.

The researchers then employed a second pre-testing to ensure the power of the items. Twelve people, who traveled to wineries in the past, were recruited to participate in the focus group. Participants were asked about factors that influenced their decisions to buy or not to buy wine and/or souvenirs at wineries. Given that gratuity purchasing may be of a subconscious nature, questions about feelings of appreciation to winery personnel, obligation, normative pressure, and other factors related to gratuity purchasing were asked both indirectly and directly. Based on the content analysis of the participants' responses both in the scenarios and the focus group, an initial list of items that could potentially be antecedents to gratuity purchasing was developed. Next, a pilot study was conducted to ensure the reliability of the instrument.

For the pilot study, the instrument was administered to visitors at a Texas winery. The data from the pilot study were analyzed to ensure the reliability of the instrument. The scale in the pilot study obtained reliability of $\alpha=.78$ for gratitude and $\alpha=.70$ for obligation. The final list of items to measure gratitude and obligation included the instruction question, "To what extent did the following factors affect your decision whether to purchase wine?" and was followed by a list of factors, (1) "desire to say "thank you" to the winery personnel"; (2) "buying wine was the socially proper thing to do"; (3) "feelings of ethical indebtedness to buy wine", (4) “purchase expectation from winery personnel", (5) “in return for wine tasting”, and (6) "in return for the tour." The items were measured on a Likert-type scale, anchored between least likely (1) and most likely (7). 
The total questionnaire contained 30 questions. In addition to the constructs that measured gratitude and obligation, the questionnaire also examined the structure of the travel group. Sociodemographic characteristics examined were gender, age, education, income, occupation, and place of residence. Behavioral characteristics examined were the total number of wineries visited in lifetime, first time versus repeat visitors, wine consumption quantities, and the amount of money spent on wine per month.

\section{ANALYSIS}

\section{Data Reduction}

The newly developed gratitude and obligation measurement was initially subjected to principal component analysis with varimax rotation. An examination of factor loadings, eigenvalues greater than one, and the scree plot suggested two factors. Factor 1 included items which measured positive affective response to receiving services at a winery, namely appreciation of the wine tasting, desire to say "thank you" to winery personnel, and appreciation of the tour (factor loadings $.81, .74, .74$, respectively). Factor 1 was labeled gratitude. Factor 2 included items which measured a negative, possibly uncomfortable, state that visitors may experience. Items on the second factor included purchase expectation from winery personnel, normative pressure, and ethical indebtedness to make a purchase (factor loadings $.82, .70, .42$, respectively). This factor was named obligation. Despite the low factor loading of one item on the obligation factor, since the loading was higher than .40 , the decision was made to retain this item. A factor loading of .40 or above as worthy inclusion in interpreting factors was offered by Stevens (1992). The two factors accounted for $55.67 \%$ of the total variance.

Correlation analysis revealed that the items of each factor showed a high degree of internal consistency indicating that the three items on each factor were measuring a single, 
similar construct (gratitude $\alpha=.87$; obligation $\alpha=73$ ). The results of the factor analysis for gratitude and obligation were consistent with previous research on dimensionality of these constructs (Goei and Boster 2005), and again confirmed that gratitude and obligation can be empirically differentiated.

\section{Sociodemographic Profile of Wine Tourists}

Descriptive statistics were employed to obtain a representation of the sample. The sociodemographic characteristics tested were gender, age, education, and income. Forty-six percent of the visitors were male, and 54\% were female. The average age of the respondents was 41 years, ranging from 21 to 69 years old. Notably, 18.5\% were younger consumers, 21 to 30 years old. This percentage represents an international trend of the wine industry, where younger consumers start to develop more interest in wine (Fountain and Charters 2004, Hammett 1997, Howard and Stonier 2002). Respondents had high levels of education. Two-thirds of the sample has earned either an undergraduate or graduate degree. Only $5.6 \%$ of the visitors had not attended college.

Participants' income levels were substantially higher than the general U.S. population, with only $16 \%$ of the sample earning less than $\$ 40,000$ as a total annual household income. Almost one-third of the respondents reported that their annual household income exceeded $\$ 100,000$. For comparison, the median income of the U.S. population in 2005 was $\$ 46,326$ (U.S. Census Bureau 2006)

Participants' residential zip codes were used to classify their places of residence. The results also indicated that $78.2 \%$ of visitors were from Texas and $21 \%$ were from other U.S. states. Less than one percent of respondents were international visitors. Overall, the sociodemographic background of visitors to Texas wineries (middle-aged, educated, and with higher 
incomes) mirrored the demographic profile of wine consumers in general (Motto Kryla \& Fisher 2000).

During their visits to the wineries, seventy-five percent of the visitors purchased wine and/or souvenirs, while $25 \%$ did not make a purchase. The mean of the total amount spent at the wineries was about thirty dollars $(M=30.29, S D=34.39)$; the median was $\$ 20.00$. The total spending represented a combined amount that visitors spent on wine and souvenirs. Wine sales per person had a mean of $\$ 27.37$ (90.4\% of sales per person), while souvenir sales per person accounted for an average of $\$ 2.92$ (9.6\% of sales per person).

\section{Dimensionality of Measures}

To answer $\mathrm{RQ}_{1}$ on the dimensionality of the gratitude and obligation measures, six items were subjected to a principal axis factoring with a varimax rotation. An examination of factor loadings, eigenvalues greater than one, and the scree plot suggested two factors, labeled gratitude and obligation. The two factors accounted for $55.67 \%$ of the total variance. No item was found with loading less than .40 .

The gratitude factor showed high loadings on the three items that measured positive affective responses to receiving services at the wineries, namely (a) desire to say "thank you" to winery personnel, (b) appreciation of the wine tasting, and (c) appreciation of the tour. The obligation factor was composed of the remaining three items that measured negative responses that is, (a) feelings of ethical indebtedness to buy wine, (b) purchase expectation from the winery personnel, and (c) normative pressure to buy wine.

Correlation analysis revealed that the items on each factor showed a high degree of internal consistency indicating that the three items loading on each factor were measuring a similar, single construct. The coefficient alphas for the gratitude and obligation factors were .87 
and .73 , respectively. The results of the factor analysis suggested that gratitude and obligation were in fact two separate constructs, and can be empirically and operationally differentiated, answering $\mathrm{RQ}_{1}$.

\section{Effects of Gratitude and Obligation on Purchasing}

$\mathrm{H}_{1}$ predicted that feelings of gratitude and obligation that wine tourists experience during their visit to a winery have an impact on visitor purchasing behavior. Specifically, the expectation was that the stronger the feelings of gratitude and obligation, the bigger the expenditures. $\mathrm{H}_{1}$ was supported.

Correlation analysis was conducted to examine the relationships between gratitude, obligation, and dollar amounts spent at wineries. The relationships were significant and positive. The correlation between gratitude and the amount of money spent at wineries was the highest $(r$ $=.51, p<.01)$. Correlation between obligation and total dollars spent at wineries was also significant $(r=.36, p<.01)$.

The results were consistent with the prediction that gratitude and obligation have an effect on tourist purchasing behavior at wineries. The findings suggest that the higher visitors' feelings of gratitude and obligation while at a winery, the more money they are going to spend on wine and/or souvenirs.

\section{Visitor Group Size and Expenditures}

$\mathrm{H}_{2}$ predicted that expenditures at wineries also depend on the number of visitors in the group. Particularly, $\mathrm{H}_{2}$ stated that the smaller the group of wine tourists, the bigger the expenditures at wineries. $\mathrm{H}_{2}$ was also supported.

Correlation analysis was employed to examine the relationship between the number of visitors in the group and dollar amounts spent at wineries. The relationship was significant and 
negative $(r=-.39, p<.01)$. As expected, as the number of people in the group increases, the dollar amount spent at wineries decreases.

Interestingly, the relationship between the visitor group size and feelings of gratitude and obligation was also significant and negative. In other words, as the number of people in the group increases, the levels of gratitude and obligation decrease. A complete correlation matrix between the variables is provided in Table 1.

\section{Insert Table 1 here}

\section{Effects of Visitor Group Size on Gratitude and Obligation}

The correlation analysis results suggested that there is a relationship between the number of visitors in the group and the levels of gratitude and obligation that visitors experience while at a winery. The fact that smaller groups spend more money at wineries may then be explained by visitor feelings of gratitude and obligation. To further explore this implication and to test $\mathrm{H}_{3}$ stating that wine tourists who visit wineries in smaller groups experience higher levels of gratitude and obligation than visitors of larger groups, a series of analyses of variance (ANOVA) was employed.

For the analysis purposes, the sample was divided into three groups in effort to keep the group sizes balanced and relatively equal: (a) visitors who traveled in groups of one or two people, (b) visitors who traveled in groups of three or four people, and (c) groups of five visitors and more. It is important to note that visitors who traveled to the wineries in larger groups typically were groups of people who knew each other (e.g., relatives, friends). The sample did not include any organized tours, where tourists would pay for their wine tasting as part of the tour price. 
The three groups served as three levels of the independent variable - number of visitors in the group. The dependent variables were the dollar amount spent at wineries, gratitude, and obligation (overall mean scores). Three one-way ANOVA were employed to determine if differences existed between the groups. The overall ANOVA results are presented in Table 2.

\section{Insert Table 2 here}

With respect to spending at wineries, the ANOVA was significant $F(2,354)=34.68, p \leq$ .001 . The number of visitors in the group factor accounted for $16 \%$ of the variance of the dependent variable. In terms of gratitude, the overall ANOVA was also significant $F(2,330)=$ $65.94, p \leq .001$. The strength of the relationship between the number of visitors in the group and the gratitude factor was strong, with the number of visitors factor accounting for $29 \%$ of the variance of the dependent variable. With regards to obligation, the overall ANOVA was significant $F(2,353)=14.51, p \leq .001$. Although the effect was significant, the obligation variable was weaker than the gratitude factor. The number of visitors in the group factor accounted for only $8 \%$ of the variance of the obligation variable.

Because the F-values were significant, post-hoc analyses were further conducted to evaluate specific differences between the groups. The mean differences between the groups for the three ANOVA are reported in Table 3.

\section{Insert Table 3 here}

The post-hoc test revealed significant differences in purchasing behavior among the three groups. Visitors who traveled in groups of one or two people spent significantly more money $(M$ $=46.61, S D=33.78)$ than visitors who traveled in groups of three or four people $(M=32.57, S D$ $=33.70)$, and especially more than groups of five or more people $(M=12.19, S D=26.77)$. 
Follow-up tests were also conducted to evaluate pairwise differences among the means for the gratitude factor. The results indicated that visitors who traveled in smaller groups (less than five people in the group) experienced stronger feelings of gratitude towards the winery personnel than those visitors who traveled in larger groups.

Post-hoc analysis was also conducted to examine the relationship between feelings of obligation to buy wine and the number of visitors in the group. Visitors of groups of one or two people and groups of three or four visitors showed similar levels of obligation to buy wine. However, visitors who traveled in groups of five and more people differed significantly from smaller groups in terms of their feelings of obligation. Larger groups reported considerably less obligation than visitors who traveled in smaller groups.

To summarize, $\mathrm{H}_{3}$ was also supported. The results of the statistical analysis indicated that wine tourists who visit wineries in smaller groups not only spend more money on wine and/or souvenirs, but also experience higher levels of gratitude and obligation than visitors of larger groups.

\section{DISCUSSION}

The findings demonstrated that gratitude and obligation are strongly correlated with visitor purchasing behavior at wineries. The research found that as feelings of gratitude and obligation increase, so does the amount of money visitors spend on wine and/or wine souvenirs.

Additional results indicated that purchasing at wineries is influenced by the presence of travel companions. In particular, the research found that purchasing at wineries differed depending on the number of visitors in the group. It appears that visitors who travel in smaller groups experience higher levels of gratitude and obligation than visitors of larger groups. 
Consequently, visitors who come to wineries in smaller groups tend to spend more money on wine and/or wine souvenirs than larger groups.

There may be several reasons that smaller groups spend more money at wineries. While not validated by the current study, one possible reason is the fact that purchasing at tasting rooms takes place in public conditions may trigger a perceived need to comply with the reciprocity norm. Cialdini (2001) claimed that reciprocation almost always unfolds in a public way. Previous research has indicated that public conditions generally create greater compliance than private conditions (Whatley et al. 1999). In other words, it is possible that when people know that their behavior is observable by other people (e.g., winery personnel) they are more likely to comply with social norms. With fewer visitors then, purchasing becomes more visible.

Therefore, visitors who come to wineries in the company of one or two people are more likely to buy wine because their purchasing is more visible to their travel companions and to the winery personnel. Alternatively, purchasing is less visible for larger groups of visitors. If visitors are aware that their purchasing behavior is less noticeable, they may feel less need to buy wine at the end of their visits.

In addition, if other people within the group have purchased wine, visitors may feel that this has discharged their obligation to buy and has provided a type of cover for them. The other companions may engage in conversation with the winery tour guide and this perhaps provides a distraction or creates an atmosphere where there is less focus and pressure to purchase.

It is also possible that visitors of larger groups have fewer chances to communicate directly with the winery personnel, and therefore, experience less gratitude and obligation to buy wine. This may be an important issue to consider as developing a personal bond or relationship 
with consumers is likely to create a greater degree of gratitude and obligation that could translate into purchases.

Additional purchases by visitors in smaller groups may also be partly caused by less crowded conditions in the tasting room and at the cash register. It is possible that, in some situations with larger groups, visitors do not want to wait in line to make a purchase and because of time constraints, simply decide to leave.

Differences in purchasing behavior between the groups may also develop from different motivational factors to visit a winery. Perhaps visitors who come in smaller groups focus more on the product characteristics. In contrast, the primary reason for visiting a winery in a large group may be socializing rather than wine. Therefore, visitors who come in larger groups may concentrate more on spending time with other people in their group rather than learning about the wine or the winery.

\section{MANAGERIAL IMPLICATIONS}

Winery managers need to be aware of and consider the effect of gratitude and obligation on visitor purchasing decisions. Since strong relationships were found between gratitude and purchasing behavior, visitors' experiences at wineries need to be enjoyable for gratitude to occur. Winery personnel need to find ways to enhance visitor feelings of gratitude.

Differences were also found between purchasing behavior of visitors of smaller and larger groups. Thus, different selling strategies seem necessary for smaller and larger groups of visitors. With larger groups, winery personnel rarely have sufficient time to communicate with each member of the group and to establish individual relationships with visitors. In the current sample, larger groups were served by one salesperson. This might be the reason that visitors of larger groups experience less appreciation of the personnel than visitors of smaller groups. This 
does not mean, however, that larger groups cannot feel grateful for their experiences at wineries. To enhance feeling of gratitude, winery management may consider more than one sales person for larger groups of visitors to help them connect with individual visitors. Since sales people at wineries often work on a part-time basis, management may require reservations for larger group of visitors to maximize efficiency of their workforce.

Although not tested in this study, it could be possible that larger groups would feel more gratitude if they've been provided with an opportunity for socializing while at a winery.

Previous research shows that spending time with other people within larger groups is one of the primary motivational factors to visit wine events (Isaykina 2001). None of the sampled wineries had picnic or dining areas within their facilities. Adding these areas may be worth managerial consideration.

\section{LIMITATIONS AND FUTURE RESEARCH}

The current research presented an innovative approach to the study of wine tourist behavior. However, there were several limitations that may have impacted the results of the study. One limitation to the present research revolved around the sampling method. The sample was limited to visitors to Texas wineries. The results of this research may be region specific. Generalizations to other wine tourism sites are not warranted. To increase generalization of the results, replication of this research in a variety of settings is recommended.

Another limitation is associated with the measurement tools. For the purposes of this research, a new scale was developed to measure gratitude and obligation. Although the new instrument performed reliably in the present study, ways to further refine the scale should be

explored. Because the instrument had not been tested previously to the research reported herein, its construct validity needs to be examined in a variety of settings. The more a construct is used 
in different settings with outcomes consistent with theory, the higher its construct validity (Agresti and Finlay 1997).

Other areas of consideration for future research are based on the assumptions drawn from the results of the current study. One suggestion was that differences in purchasing behavior between smaller and larger groups of visitor may develop from different motivational factors to visit a winery. Motivations for visiting tasting rooms were beyond the scope of the current research, but it is likely that a combination of motivations and group dynamics play an important part in purchase activities. Future studies are necessary to determine whether differences in motivational factors exist between smaller and larger groups of visitors.

Another recommendation for future studies includes testing the effect of a number of additional variables that may have an impact on the levels of gratuity purchasing. These variables may include factors such as whether or not a winery charges a fee for wine tasting. Possible extension to the current study would be the analysis of organized tours purchasing behavior. It is possible that the feeling of obligation would be diminished if tourists have already paid for their wine tasting as part of the tour price. Also, the number of wines served in a tasting may have an effect on the levels of gratitude and obligation.

Finally, the financial implications for wineries may be very significant. Future studies should examine the impact of adding staff to potentially increase gratitude and increase revenue. Developing a break-even point that would show where the optimum level of staffing is would be a useful study. However, a careful examination of the total expenses of this approach should be undertaken as additional costs of staff training and supervision would need to be considered, as well as salary costs.

\section{CONCLUSIONS}


The purpose of the research was to investigate the role that gratitude and obligation play in wine and/or wine souvenir purchases at wineries. Specifically, the study examined whether differences in visitor purchasing behavior existed based on their feelings of gratitude and obligation while at a winery.

The results of the current study empirically supported reciprocity theory and previous experimental evidence that people feel a need to reciprocate for what they have received. In the tasting room visit condition, when visitors find their experiences at wineries enjoyable, they are likely to develop a sense of gratitude and possibly a sense of obligation to return hospitality provided by the winery personnel. These feelings, in turn, may lead to a perceived need to buy wine and/or wine souvenirs at the end of their visits - that is, gratuity purchasing.

Additionally, the study investigated whether visitors of smaller and larger groups differ in terms of the amount of money they spend at wineries and with respect to feelings of gratitude and obligation. The results indicated that visitors who travel to wineries in smaller groups feel more grateful to winery personnel and more obliged to buy wine than those visitors who traveled in larger groups. Accordingly, visitors who travel in smaller groups tend to spend more money at wineries than larger groups.

Overall, the primary purpose of this study was to add to the knowledge about wine tourists as no previous studies were located which examined the role of reciprocity in the wine industry. This research provided sufficient empirical evidence to suggest that gratitude and obligation impact visitor purchasing decisions at wineries. It is hoped that additional work will build on this initial effort to explain the effect of the reciprocity norm on consumer behavior. 


\section{REFERENCES}

Agresti, Alan, and Barbara Finlay (1997). Statistical Methods for the Social Sciences. (3rd ed.). Upper Saddle River, NJ: Prentice Hall.

Bar-Tal, Daniel, Yaakov Bar-Zohar, Martin S. Greenberg, and Margarete Hermon (1977).

"Reciprocity Behavior in the Relationship between Donor and Recipient and between Harm-Doer and Victim." Sociometry, 40: 293-98.

Barclay, Veronica (May 2006). "2006 Tasting Room Survey Report." Wine Business Monthly, $42-48$.

Berkowitz, Leonard (1972). "Social Norms, Feelings, and Other Factors Affecting Helping and Altruism." In Advances in Experimental Social Psychology, edited by Leonard Berkowitz, pp. 63-108. San Diego, CA: Academic.

Boster, Franklin J., Jose I. Rodriguez, Michael G. Cruz, and Linda Marshall (1995). "The Relative Effectiveness of a Direct Request Message and a Pre-Giving Message on Friends and Strangers." Communication Research, 22 (4): 475-84.

Bruwer, Johan, Elton Li, and Mike Reid (2002). "Segmentation of the Australian Wine Market Using a Wine-Related Lifestyle Approach." Journal of Wine Research, 13 (3): 217-42.

Charters, Stephen, and Jane Ali-Knight (2002). "Who Is the Wine Tourist?" Tourism Management, 23 (3): 311-19.

Churchill, Gilbert A. (1979). Marketing Research: Methodological Foundations (2nd ed.). Hinsdale, IL: Dryden Press.

Cialdini, Robert B. (2001). Influence: Science and Practice. (4th ed.). Boston, MA: Allyn and Bacon. 
Cialdini, Robert B., and Kelton vL. Rhoads (2001). "Human Behavior and the Marketplace: What Makes Customers Say "Yes" To a Purchase Request?" Marketing Research, 13 (3): $8-13$.

Dodd, Tim H., and Veronique Bigotte (1997). "Perceptual Differences among Visitor Groups to Wineries." Journal of Travel Research, 35 (3): 46-51.

Dodd, Tim H., and A. William Gustafson (1997). "Product, Environment, and Service Attributes That Influence Consumer Attitudes and Purchases at Wineries." Journal of Food Products Marketing, 4 (3): 41-59.

Dodd, Tim H., Natalia Kolyesnikova, and Min-Hwan Choi (2005). "A Profile of the Texas Wine and Wine Grape Industry." Texas Wine Marketing Research Institute Pub. 06-01. Texas Tech University, Lubbock, TX.

Dodd, Tim H., Debra A. Laverie, Jim F. Wilcox, and Dale F. Duhan (2005). "Differential Effects of Experience, Subjective Knowledge and Objective Knowledge on Sources of Information Used in Consumer Wine Purchasing." Journal of Hospitality and Tourism Research, 29 (1): 3-19.

Elster, Jon (1989). The Cement of Society: A Study of Social Order. Cambridge, England: Cambridge University Press.

Emmons, Robert A., and Cheryl A. Crumpler (2000). "Gratitude as a Human Strength: Appraising the Evidence." Journal of Social and Clinical Psychology, 19: 56-69. Fountain, Joanna, and Stephen Charters (2004)."Younger Wine Tourists: A Study of Generational Differences in the Cellar Door Experience." Paper presented at the International Wine and Tourism Conference, Margaret River, Australia. 
Gitelson, Richard J., and John L. Crompton (1983). "The Planning Horizons and Sources of Information Used by Pleasure Vacationers." Journal of Travel Research, 21 (2): 2-7.

Goei, Ryan, and Franklin J. Boster (2005). "The Roles of Obligation and Gratitude in Explaining the Effect of Favors on Compliance." Communication Monographs, 72: 284-300.

Gouldner, Alvin W. (1960). "The Norm of Reciprocity: A Preliminary Statement." American Sociological Review, 25 (2): 161-78.

Graham, Susan A. (1988). "Children's Developing Understanding of the Motivational Role of Affect: An Attributional Analysis." Cognitive Development, 3: 71-88.

Greenberg, Martin S., and David M. Frisch (1972). "Effect of Intentionality on Willingness to Reciprocate Favor." Journal of Experimental Social Psychology, 8: 99-111.

Greenberg, Martin S., and Leonard Saxe (1975). "Importance of Locus of Help Initiation and Type of Outcome as Determinants of Reactions to Another's Help Attempt." Social Behavior and Personality, 3: 101-10.

Groves, Ronald, Stephen Charters, and Coral Reynolds (2000). "Imbibing, Inscribing, Integrating and Imparting: A Taxonomy of Wine Consumption Practices." Journal of Wine Research, 11 (3): 209-22.

Hall, C. Michael, Liz Sharples, Brock Cambourne, and Niki Macionis (2000). Wine Tourism around the World: Development, Management and Markets. Woburn, MA: Butterworth Heinemann.

Hall, John E., and Larry Lockshin (1999). "Understanding Wine Purchasing - It's Not the Consumer, It's the Occasion." Australian and New Zealand Wine Industry Journal, 14 (3): 69-78. 
Hall, John E., and Maxwell Winchester (2000). "What's Really Driving Wine Consumers?" Australian and New Zealand Wine Industry Journal, 15 (4): 68-72.

Hammett, Jim (1997). Young, Marginal Wine Drinkers Form Target for Researchers Eager to Expand Wine Audience.

http://winebusiness.com/Archives/Monthly/1997/9710/bmj9718.htm. (accessed December 28, 2005).

Holbrook, Morris B. , J. O‘Shaughnessy, and Stephen Bell (1990). "Actions and Reactions in the Consumption Experience: The Complementary Roles of Reasons and Emotions in Consumer Behavior." Journal of Consumer Behaviour, 4: 131-63.

Howard, Daniel J. (1995). "Chaining the Use of Influence Strategies for Producing Compliance Behavior." Journal of Social Behavior and Personality, 10 (1): 169-85.

Howard, Roz, and Jenny Stonier (2002). "Marketing Wine to Generation X." Australian and New Zealand Wine Industry Journal, 17 (3): 78-82.

Hsu, Cathy H.C., Soo K. Kang, and Terry Lam (2006). "Reference Group Influences among Chinese Travelers." Journal of Travel Research, 44 (4): 474-84.

Isaykina, Elena (2001). "Defining the Target Market and Motivations for Visiting the Grapefest Wine Festival in Grapevine, Texas." Master of Science, Texas Tech University, Lubbock, Texas.

Jenkins, Roger L. (1978). "Family Vacation Decision-Making." Journal of Travel Research, 16 (4): 2-7.

Kang, Soo K., and Cathy H.C. Hsu (2004). "Spousal Conflict Level and Resolution in Family Vacation Destination Selection." Journal of Hospitality \& Tourism Research, 28 (4): 408-24. 
Laesser, Christian, and Geoffrey I. Crouch (2006). "Segmenting Markets by Travel Expenditure Patterns: The Case of International Visitors to Australia." Journal of Travel Research, 44 (4): $397-406$.

Litvin, Stephen W., Gang Xu, and Soo K. Kang (2004). "Spousal Vacation-Buying Decision Making Revisited across Time and Place." Journal of Travel Research, 43 (2): 193-98. McCall, George J., and Jerry L. Simmons (1978). Identities and Interactions: An Examination of Human Associations in Everyday Life. New York, NY: Free Press.

McCullough, Michael E., Shelley D. Kilpatrick, Robert A. Emmons, and David B. Larson (2001). "Is Gratitude a Moral Affect?" Psychological Bulletin, 127 (2): 249-66.

Mitchell, Richard, C. Michael Hall, and Alison McIntosh (2000). "Wine Tourism and Consumer Behavior." In Wine Tourism around the World: Development, Management, and Markets, edited by C. Michael Hall, Liz Sharples, Brock Cambourne and Niki Macionis, pp. 115-35. Woburn, MA: Butterworth-Heinemann.

Motto Kryla \& Fisher, LLP (2006). "Economic Impact of California Wine." The Wine Business Center, St. Helena, CA.

(2000). "U.S. Wine Demographics Report." The Wine Business Center, St. Helena, CA.

Pervan, Simon, Liliana Bove, and Lester W. Johnson (2004)."Conceptualizing the Role of Reciprocity in Relationship Marketing: An Examination of Its Supporting Virtues." Paper presented at the Australian and New Zealand Marketing Academy Conference, Wellington, New Zealand.

Regan, Dennis T. (1971). "Effects of a Favor and Liking on Compliance." Journal of Experimental Social Psychology, 7: 627-39. 
Simpson, John A, and Edith Weiner (1989). The Oxford English Dictionary. (2nd ed.): New York, NY: Clarendon Press.

Snepenger, David, Kelli Meged, Mary Snelling, and Kelly Worrall (1990). "Information Search Strategies by Destination-Naive Tourists." Journal of Travel Research, 29 (1): 13-16.

South African Wine Industry Information \& Systems (2004). Macro-Economic Impact Study of the Wine Industry on the Western Cap.

http://www.sawis.co.za/SAWISPortal/uploads/Macro-eco\%20impact\%20studysummary2004.pdf. (accessed December 5, 2005).

Spawton, Anthony L. (1991). "Grapes and Wine Seminar - Prospering in the 1990s: Changing Your View of the Consumer." International Marketing Review, 8 (4): 32-43.

Stevens, James (1992). Applied Multivariate Statistics for the Social Sciences. (2nd ed.). Hillsdale, NJ: Erlbaum Associates.

U.S. Census Bureau (2006). Income, Poverty, and Health Insurance Coverage in the United States: 2005. http://www.census.gov/prod/2006pubs/p60-231.pdf. (accessed December $28,2006)$.

Voss, P. Jr. (1984). "Status Shifts to Peer Influence." Advertising Age, 17 (May): 1-10.

Ward, Scott (1974). "Consumer Socialization." Journal of Consumer Research, 1: 1-14.

Whatley, Mark A., J. Matthew Webster, Richard H. Smith, and Adele Rhodes (1999). "The Effect of a Favor on Public and Private Compliance: How Internalized Is the Norm of Reciprocity?" Basic and Applied Social Psychology, 21 (3): 251-59.

Winemakers Federation of Australia (2005). A Recipe for Success: Wine and Tourism Blend for Regional Prosperity. http://www.wfa.org.au/PDF/press 18.05.05.pdf. (accessed December 5, 2005). 
Yuan, Jingxue, and Tim H. Dodd (2001)."Exploring Relationship between Country of Origin Effect and Wine Purchase Involvement." Paper presented at the Sixth Annual Graduate Education and Graduate Research Conference in Hospitality and Tourism, Atlanta, GA. 
TABLE 1

CORRELATION MATRIX

\begin{tabular}{|c|c|c|c|c|}
\hline & Gratitude & Obligation & $\begin{array}{l}\text { Number of visitors } \\
\text { in the group }\end{array}$ & $\begin{array}{l}\text { Dollar amount } \\
\text { spent at wineries }\end{array}$ \\
\hline Gratitude & - & $.59 * *$ & $-.51 * *$ & $.51 * *$ \\
\hline Obligation & & - & $-.26^{* *}$ & $.36^{* *}$ \\
\hline $\begin{array}{l}\text { Number of visitors } \\
\text { in the group }\end{array}$ & & & - & $-.39 * *$ \\
\hline $\begin{array}{l}\text { Dollar amount spent } \\
\text { at wineries }\end{array}$ & & & & - \\
\hline
\end{tabular}

$* * p<.01$

Note: Items on the gratitude and obligation scales anchored between least likely (1) and most likely (7) 
TABLE 2

ANALYSES OF VARIANCE FOR SPENDING, GRATITUDE, AND OBLIGATION

\begin{tabular}{|c|c|c|c|c|}
\hline & $d f$ & $F$ & $\eta^{2}$ & $p$ \\
\hline Dollar amount spent at wineries & $\begin{array}{c}2 \\
354\end{array}$ & 34.68 & .16 & .001 \\
\hline Gratitude & $\begin{array}{c}2 \\
330\end{array}$ & 65.94 & .29 & .001 \\
\hline Obligation & $\begin{array}{c}2 \\
353\end{array}$ & 14.51 & .08 & .001 \\
\hline
\end{tabular}


TABLE 3

MEAN DIFFERENCES

FOR ANALYSES OF VARIANCE BETWEEN GROUPS

\begin{tabular}{lclllll}
\hline \hline & \multicolumn{5}{c}{ Dependent Variables } \\
\cline { 2 - 7 } $\begin{array}{l}\text { Independent variable } \\
\begin{array}{l}\text { Number of visitors in } \\
\text { the group) }\end{array}\end{array}$ & $\begin{array}{c}\text { Dollar amount spent at } \\
\text { wineries per person }\end{array}$ & Gratitude & Obligation \\
\cline { 2 - 8 } & Mean $^{1}$ & SD & Mean $^{1}$ & SD & Mean & SD \\
\hline $1-2$ visitors & $44.61_{\mathrm{a}}$ & 33.78 & $5.23_{\mathrm{a}}$ & 1.41 & $3.76_{\mathrm{a}}$ & 1.63 \\
$3-4$ visitors & $32.57_{\mathrm{b}}$ & 33.70 & $4.93_{\mathrm{a}}$ & 1.45 & $3.56_{\mathrm{a}}$ & 1.50 \\
5 and more visitors & $12.19_{\mathrm{c}}$ & 26.77 & $3.08_{\mathrm{b}}$ & 1.73 & $2.79_{\mathrm{b}}$ & 1.33 \\
\hline
\end{tabular}

${ }^{1}$ Means with different subscripts differ significantly at $p<.05$ in the Tukey honestly significant difference comparison

Note Items on the gratitude and obligation scales anchored between least likely (1) and most likely (7) 